\title{
Comparative Study of Modified Alvarado Score and Ultrasonography in the Diagnosis of Acute Apppendicitis
}

\author{
Narendra $\mathrm{JB}^{2}$,Vinayak Thakkannavar ${ }^{1}$ \\ ${ }^{I}$ (Assistant professor Department of Surgery, Mysore Medical College and Research Institute, India) \\ ${ }^{2}$ (Surgical resident, Department of Surgery, Mysore Medical College and Research Institute, India)
}

\begin{abstract}
Objectives : To compare the accuracy of modifiedalvarado score and ultrasonography in the diagnosis of acute appendicitis to reduce the morbity and mortalityfromappendicitis and alsoreduce the negativeappendicectomy rates.

Methods : The studyincludes patients whopresented to ourhospitalwithfeatures of acute appendicitis and 50 patients whounderwentappendicectomywereincluded in the study. Patients underwentthoroughclinicalexamination and investigations. Data includingmodifiedalvarado score, ultrasonography and histopathologywerecollected and statisticalanalysisperformed.

Results :Our study showed that out of 50 patients who underwent appendicectomy, 44patients had an inflamed appendix, while 6 patients had normal appendix making the negative appendicectomy rate of 12\%. Modified Alvarado score had a sensitivity and specificity of 93.18 and 33.3, while ultrasongraphy had 88.6 and 66.6 respectively. PPV and NPV for modified Alvarado score were $91.1 \& 40$ and ultrasonography were 95.1 \& 44.4.

Conclusion :MAS is a better tool at diagnosing appendicitis than USG while USG is better at confirming the diagnosing or to rule out the possibility of appendicitis. Together MAS and USG can reduce the negative appendicectomy rate significantly.
\end{abstract}

Keywords: acute appendicitis, comparative study, modified Alvarado score, ultrasonography.

\section{Introduction}

Acute appendicitis is one of the commonest presentations that requires emergency surgery. It has a lifetime risk of about 6-7\%. It may progress to perforation which is associated with higher morbidity and mortality. Hence surgeons are inclined to operate when diagnosis is probable rather than to wait till it is certain ${ }^{1}$. The accuracy of clinical examination has been reported to range from 71-97\% and varies greatly depending on the experience of examiner ${ }^{2}$. However, because missed perforated appendix has dire consequences, surgeons have traditionally accepted a $20 \%$ rate of negative appendectomy (removal of normal appendix in patients with other causes of abdominal pain). ${ }^{3,4}$

Attempts to increase the diagnostic accuracy in acute appendicitis have included various scoring systems, computer aided diagnosis, imaging by ultrasonography and even radioactive isotope imaging. This study is aimed at comparing the accuracy of modified Alvarado score and ultrasonography in the diagnosis of acute appendicitis.

\section{Methodology}

Methods of collection of data: Methodical documentation of data by personal interview method to elicit history, detailed clinical examination, relevant investigations and management of patients admitted in surgery department of K R Hospital, mysore.

Modified Alvarado score(MAS) of 7 or more and ultrasonography(USG) showing features of acute appendicitis was considered positive. Appendicectomy was performed and histopathology(HPE) was taken as gold standard and the results were compared along with statistical analysis.

Inclusion criteria: All patients with provisional diagnosis of acute appendicitis and who are willing for surgery

Exclusion criteria: Patients with generalized peritonitis, Patients with appendicular mass/abscess

Study duration: 18 months; from DECEMBER 2014 to MAY 2016

Sample size: 50

\section{Results}

Statistical analysis was performed with modified alvarado scores, ultrasonography and histopathology reports of 50 patients. MAS was positive $(\geq 7)$ in 45 patients while USG was positive in 41 patients. HPE reports showed 44 patients had appendicitis while other 6 had normal appendix. 
Table 1.

\begin{tabular}{|l|l|l|l|}
\hline & Appendicitis(HPE) & Not appendicitis(HPE) & Total \\
\hline MAS positive & 41 & 4 & 45 \\
\hline MAS negative & 3 & 2 & 5 \\
\hline & 44 & 6 & 50 \\
\hline
\end{tabular}

41 (true positive) patients who had MAS 7 or more had appendicitis on histopathology while 4(false positive) had a normal appendix; 3(false negative) patients with MAS less than 7 had appendicitis and 2(true negative) had a normal appendix removed.

Table 2.

\begin{tabular}{|l|l|l|l|}
\hline & Appendicitis(HPE) & Not appendicitis(HPE) & Total \\
\hline USG positive & 39 & 2 & 41 \\
\hline USG negative & 5 & 4 & 9 \\
\hline & 44 & 6 & 50 \\
\hline
\end{tabular}

Out of 44 patients who actually had appendicitis, 39(true positive) were positive on USG while 5(false negative) were missed; while 2(false positive) patients were positive on USG who had a normal appendix.

fig.1

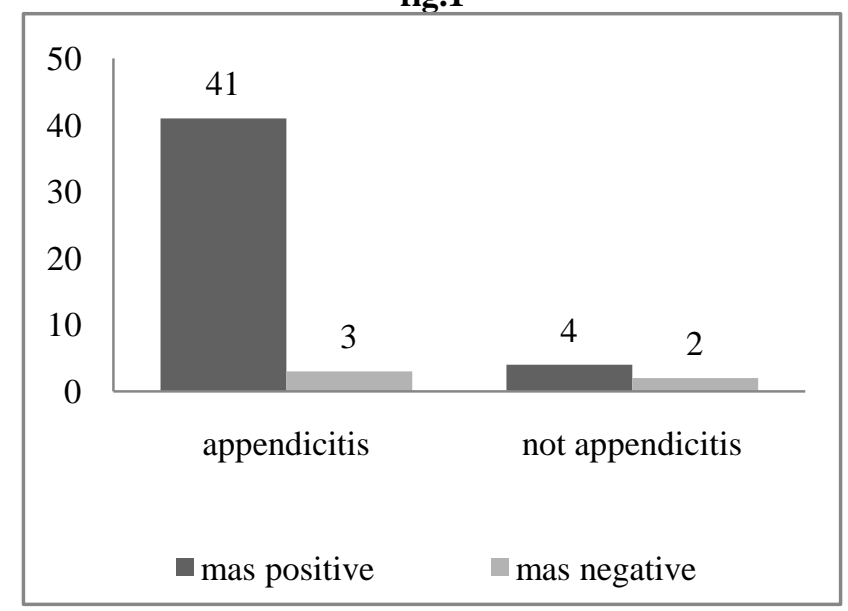

fig.2

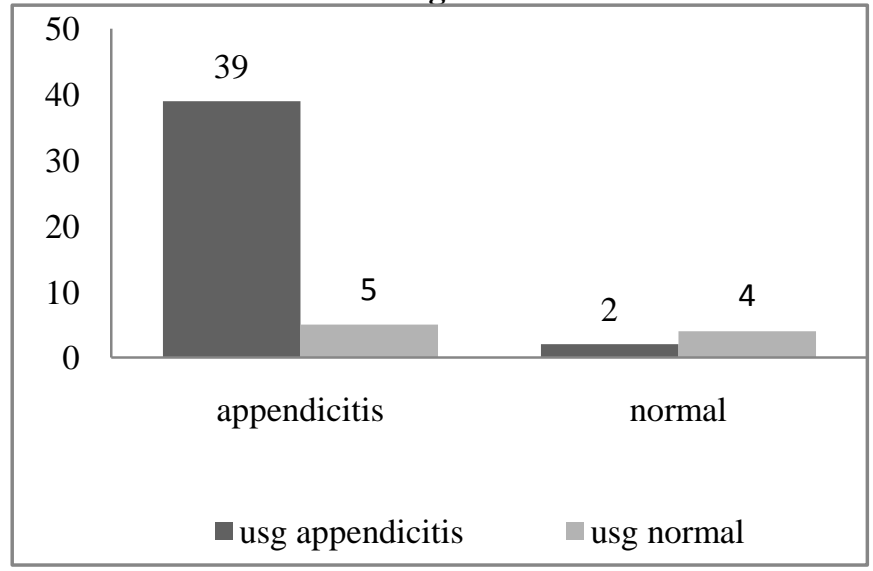

Table 3. comparison of diagnostic variables of MAS and USG

\begin{tabular}{|l|l|l|}
\hline & MAS & Ultrasonography \\
\hline Sensitivity & 93.18 & 88.64 \\
\hline Specificity & 33.33 & 66.67 \\
\hline Positive predictive value & 91.11 & 95.12 \\
\hline Negative predictive vaue & 40 & 44.4 \\
\hline Positive likelihood ratio & 1.4 & 2.67 \\
\hline Negative likelihood ratio & 0.2 & .17 \\
\hline
\end{tabular}




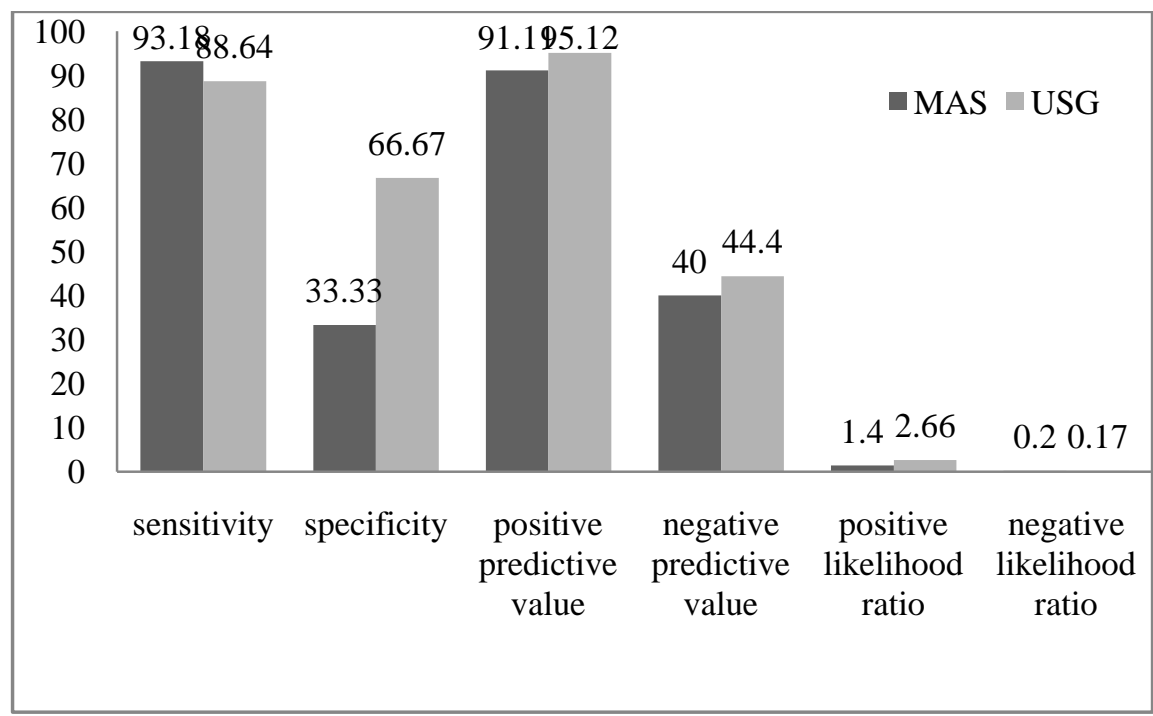

Fig.3 comparison of diagnostic variables of MAS and USG

\section{Discussion}

Appendicitis needs to be considered in the differential diagnosis of almost every patient with acute abdominal pain. Early diagnosis remains the most important goal in these patients and is made in most cases based only on history and clinical examination. The typical presentation begins with periumbilical pain due to irritation of visceral nerves. Followed by anorexia and nausea. The pain then localizes to right lower quadrant as inflammatory process involves parietal peritoneum overlying appendix. Fever ensues, followed by development of leukocytosis.

Modified Alvarado Score:Alvarado described a scoring system in 1986 which was later modified by kalan et al to modified Alvarado score. The scoring system involves following components with a total score of 9. A score of 7 or more is considered high probability for appendicitis

\begin{tabular}{|l|c|}
\hline \multicolumn{1}{|c|}{ Symptoms / signs / investigation } & yes \\
\hline Migration of pain to right iliac fossa & 1 \\
\hline Anorexia & 1 \\
\hline Nausea/ vomiting & 1 \\
\hline Tenderness over right iliac fossa & 2 \\
\hline Rebound tenderness over right iliac fossa & 1 \\
\hline Temperature $>37.3$ C & 1 \\
\hline Leukocytosis $>10,000 /$ cu.mm & 2 \\
\hline Total & 9 \\
\hline
\end{tabular}

Ultrasonography:Sonographicfindingsconsistent with acute appendicitis include an appendix of $7 \mathrm{~mm}$ or more in anteroposterior diameter, a thick-walled, noncompressibleluminal structure seen in cross section, referred toas a target lesion, or the presence of an appendicolith ${ }^{6}$

The statistical analysis of our study showed that out of 50 patients who underwent appendicectomy, 44 had an inflamed appendix while 6 had normal appendix making the negative appendicectomy rate of $12 \%$.

MAS had higher sensitivity i.e. ability to identify appendicitis correctly was better than ultrasonography; while specificity was more for ultrasonography i.e. ultrasonography could rule out appendicitis better than MAS. Out of 44 appendicitis patients, 2 patients which would have been missed by ultrasonography were diagnosed by MAS whereas 4 patients who underwent appendicectomy had normal appendix were incorrectly diagnosed as appendicitis by MAS but had normal report on USG.

The positive predictive value and negative predictive value of MAS (91.1 \& 40) was found to be slightly lower than that of USG (95.1 \& 44.4). It shows that probability of appendicitis in positive USG is more than positive MAS. Also probability of patient being not a case of appendicitis is more in negative USG than negative MAS.

Positive likelihood ratio for USG was higher than that of MAS while the negative likelihood ratio was slightly higher for MAS. 
Emmanuel S Kanumbaet al conducted a study in which they reported sensitivity and specificity of MAS as $94.1 \%$ and $90.4 \%$ respectively. The study shows that use of MAS in patients suspected to have acute appendicitis provides a high degree of diagnostic accuracy. However, if the patient presents with an atypical presentatin additional investigations may be required to confirm the diagnosis. ${ }^{5}$

Another study conducted by Ramachandra et al showed that high scores (7-9) in modified Alvarado Score can be used as a dependable aid in early diagnosis of acute appendicitis in children and men, but not in women.USG abdomen is a useful tool in diagnosis of appendicitis (HPR positive) in patientswith a MAS of 5or6. ${ }^{6}$

A study conducted by Bilbey JH et al on sensitivity of USG in acute appendicitis concluded that USG has sensitivity of $87 \%$, specificity of $95 \%$ and accuracy $92 \%$ and it can be used as a reliable adjunct in the evaluation of appendicitis. ${ }^{7}$

Marilyn J. Siegel et al in their study concluded that approximately half of children referred for suspected appendicitis will have a final diagnosis of abdominal pain of unknown origin. In the remaining patients, ultrasonography is useful, both to establish the diagnosis of appendicitis and to help in diagnosing other causes of acute abdominal pain. ${ }^{8}$

In a study conducted by David $\mathrm{S}$. wade et al, it was reported that the overall accuracy of ultrasonography in the diagnosis of appendicitis was statistically superior to that of the surgeon's clinical impression $(\mathrm{P}<.0001)$. However, $24 \%$ of the patients with normal ultrasound findings were ultimately found to have appendicitis at the time of surgery, emphasizing the point that ultrasonography cannot be relied on to the exclusion of the surgeon's careful and repeated evaluation.

\section{Conclusion}

The study shows that MAS is a better tool at diagnosing appendicitis than USG while USG is better at confirming the diagnosing or to rule out the possibility of appendicitis. So neither one is superior over the other tool. Any case of appendicitis can be diagnosed as appendicitis on the basis of MAS alone and treated surgically and in the doubtful cases USG can be used to rule out any other cause. Together MAS and USG can reduce the negative appendicectomy rate significantly.

\section{References}

[1]. Hoffmann J. Rasmussen O. Aids in the diagnosis of acute appendicitis. Br J surg 1989; 76:774-779

[2]. John H, Neff U, Kelemen M. Appendicitis diagnosis today: clinical and ultrasonic deductions. World J surg 1993; 17:243-249

[3]. Jones PF. Suspected acute appendicitis: trends in management over 30 years. Br J surg2001; 88:1570-1577

[4]. Lee SL, Walsh AJ, Ho HS, computed tomography and ultrasonography do not improve and may delay the diagnosis and treatment of acute appendicitis. Arch surg2001; 136:556-561

[5]. Emmanuel S Kanumba, Joseph B Mabula, Peter Rambau and Phillipo L Chalya. Modified alvarado scoring system for diagnosis of acute appendicitis. BMC Surg. 2011; 11:4

[6]. Ramachandra J, Sudhir M, Sathyanarayana. Evaluation of modified alvarado score in preoperative diagnosis of acute appendicitis. Journal of evolution of medical and dental sciences. 2013; 46:9029

[7]. Bilbey JH, Gibney RG, Cooperberg PL. Ultrasonography in acute appendicitis. Canadian Association of Radiologists Journal 1989, 40(1):22-24

[8]. Marilyn J. Siegel, MD; Celia Carel, MD; Stephen Surratt, MD. Ultrasonography of acute abdominal pain in children. JAMA. 1991;266(14):1987-89

[9]. David S. Wade, MC, USN; Stephen E. Morrow, MD; Zubin N. Balsara, MD; Thomas K Burkhard, MD; Walter B. Goff, DO. Accuracy of ultrasound in the diagnosis of acute appendicitis compared with surgeons clinical impression. Arch Surg. 1993;128(9):1039-1046 